\title{
Endotracheal tube exchange and pneumothorax: A case report
}

\author{
Nissar Shaikh ${ }^{1^{*}}$, Kasif Mahmood ${ }^{2}$, Amr Aboul Wafa $^{3}$, Ousama Kokash $^{2}$ \\ ${ }^{1}$ Department of Anesthesia/ICU, Weill Cornell Medical College in Qatar, Doha, Qatar; \\ *Corresponding Author: smaheboob@hmc.org.qa \\ ${ }^{2}$ Department of Anesthesia/ICU, Hamad Medical Corporation, Doha, Qatar \\ ${ }^{3}$ Department of Surgery, Hamad Medical Corporation, Doha, Qatar
}

Received 1 March 2013; revised 20 April 2013; accepted 4 May 2013

Copyright (C) 2013 Nissar Shaikh et al. This is an open access article distributed under the Creative Commons Attribution License, which permits unrestricted use, distribution, and reproduction in any medium, provided the original work is properly cited.

\section{ABSTRACT}

Endotracheal intubation and extubation in intensive care unit (ICU) patients are difficult. Extubation will be more worrisome if patient has difficult intubation, sleep apnea, surgical procedure involving airway or surrounding structures. In such extubation airway exchange catheters (AEC) are used, as they are simple to use and able to provide oxygen to the patient. Rarely AEC use can cause potential life threatening complications. We report a case of pneumothorax following use of AEC in post-thyroidectomy patient. Case: A 32 years old male patient was admitted to our ICU, with difficult intubation after thyroidectomy. He was a known case of obstructive sleep apnea, hypertension and large goiter. In ICU for proper visualization of vocal cords and resecuring the airway, AEC was used, but patient had hypoxia with bradycardia. He was recovered with Ambu bag ventilation and required brief cardiopulmonary resuscitation. Post resuscitation he had left impending tension pneumothorax and lung laceration requiring chest drain, which was removed after tracheostomy and weaned from the ventilator. After 9 days supra glottic edema subsided and vocal cords were moving; His trachea was decanulated and he was discharged home. Conclusion: Rarely AEC use can cause life threatening injuries. Pneumothorax following the use of AEC is not always due to tracheobronchial injury; it can also occur as a result of alveolar injury.

Keywords: AEC; Difficult Intubation; Pneumothorax; Thyroidectomy

\section{INTRODUCTION}

Tracheal tube exchange catheters (AEC) are used frequently for exchange of the endotracheal tubes. If patients is admitted to the intensive care (ICU) after airway or airway surrounding structures surgery with difficult intubation to the intensive care unit (ICU); we expect difficult extubation of these patients. AEC are used in these type of patients for safe extubation and if required resecuring of the airway. AEC use thought to be simple and safe procedure but literature describes use of AEC in ICU as a risky procedure and in majority of the patients its use failed to exchange the endotracheal tube and even causing cardiac arrest [1]. Barotrauma and pneumothorax following the use of AEC is commonly considered to be as a result of tracheobronchial injuries. We report a case of pneumothorax with the use of AEC without any airway injury in a post thyroidectomy patient.

\section{ILLUSTRATED CASE}

A 32 years old sudani male patient known case of hypertension, obstructive sleep apnea and large multi-no dular goiter; goiter was associated with respiratory symptoms (difficulty in breathing and choking sensation). He underwent total thyroidectomy; tracheal intubation was difficult (Cormack and Lehan laryngoscopic view grade IV). Intraoperative period was uneventful and he was extubated in the operating suit, but immediately developed upper airway obstruction, desturated and became restless; managed to reintuabate with difficulty. He was shifted to surgical intensive care unit (SICU) for further management.

He was ventilated with appropriate sedation and analgesia, steroids were added. On day 2 the fibre-optic laryngoscopy was inconclusive due to excessive secretions and Video-laryngoscopy showed immobile left vocal cord, supra glotic airway collapse and arytenoids car- 
tilage edema. Video laryngoscopy was repeated on day 5 , showed supra glottic edema, difficult to asses vocal cord movements. It was decided to extubate him on tube exchanger (C-CAE-19 Cook), to asses vocal cord properly and if required resecure the airway. AEC was inserted up to 30 mark, supplemented with 6 liters/minute oxygen and about to extubate, patient desturated oxygen saturation $\left(\mathrm{SPO}_{2}\right)$ dropped to $70 \%$, had bradycardia (HR 40/minute) and hypotension (systolic blood pressure 70 $\mathrm{mm}$ of $\mathrm{Hg}$ ); immediate cardiorespiratory resuscitation started, AEC was removed and $\mathrm{Ambu}^{\circledR}$ bag ventilation done. Within 2 minute $\mathrm{SPO}_{2}, \mathrm{HR}$ and blood pressure improved and became normal but we noticed decreased left side chest movements with reduced air entry. Chest $\mathrm{X}$-ray showed left pneumothorax (Figure 1), a chest drain inserted. Left lung was well expanded in post chest drain X-ray but there was a localized, elongated air filled cavity (Figure 2) suggestive of lung laceration, which disappeared after 24 hours. Fibro-optic bronchoscopy did not show any tracheobronchial injury. He had tracheostomy on day 8. Post tracheostomy video laryngoscopy



Figure 1. Chest X-ray showing tension pneumothorax.

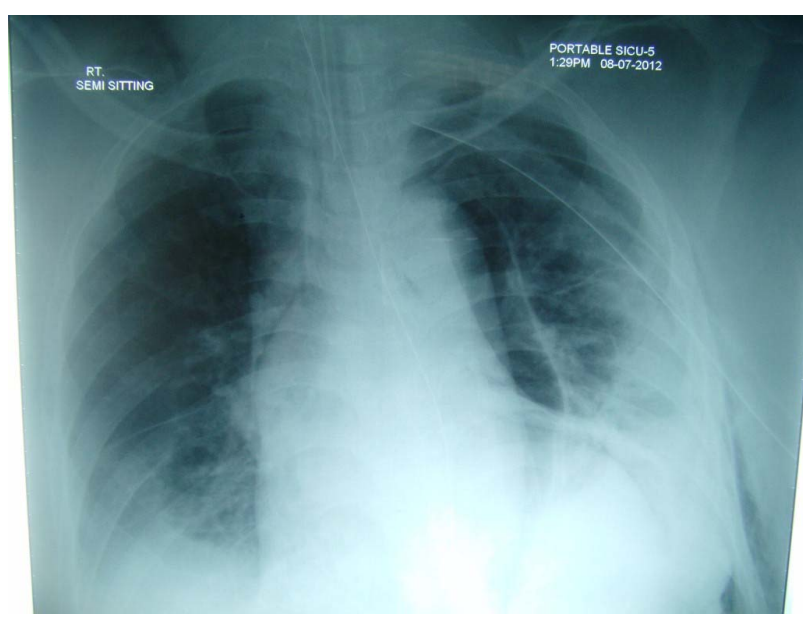

Figure 2. Left lung laceration (cylinerical air filled cavity). showed both vocal cord adducted and presence of supraglottic edema. He was weaned of from ventilator by day 10 , remained hemodynaemically stable and fully awake. He was transferred to the ward on day 12. On day 21 ; laryngoscopy showed resolution of supraglottic edema, normal vocal cord movements. He was decanulated on day 22, and discharged home to be followed in the out patient clinics.

\section{DISCUSSION}

About nineteen percent of the intensive care patients will require reintubation, but resecuring the post extubation airway is challenging and occasionally life threatening in the intensive care unit (ICU) patients, as these patients have exhausted oxygen reserve, already in respiratory distress, presence of secretion, blood in the airway and airway edema [2]. In these patients various devices such as rigid endotracheal tube guide, nasogastric tubes or airway exchange catheters (AEC) are used to facilitate extubation and if required safe reintubation [3].

Airway exchange catheters (AEC) are commonly preferred for exchange of endotracheal tube as they are simple to use, having a blunt tip, with facility to provide oxygen and ventilate if required [2]. Inspite of all these advantages of AEC, its use can cause life threatening complications such as tracheobronchial injuries, pneumothorax, esophageal intubation and failure to secure the airway [4]. Grossly the complications with use of AEC are divided into barotraumas and failure to successfully exchange the endotracheal tube over AEC. The basic etiology for the barotraumas is either tracheobroncheal injury or when the air entry exceeds the air exist from the lungs leading to hyperinflation [2].

Mort et al. in their land mark study reported that complications with the use of AEC's are more than what we expect, following its use 60\% developed hypoxia, 53\% had esophageal intubation and loss of airway, $8 \%$ developed bradycardia due to hypoxia and one patient had cardiorespiratory arrest [1].

Tracheobronchial laceration and pneumothorax are the life threatening injuries reported with the use of AEC. There are more than one (tracheobronchial laceration) reasons for the occurrence of pneumothorax following the use of AEC. First and foremost reason is passage of AEC through the Murphy's eye of endotracheal tube leading to tracheobronchial laceration and causing pneumothorax [5]. Second reason is use of jet ventilation with AEC, leading to sudden higher airway pressures and no sufficient room for exhalation causing barotrauma and pneumothorax. Third reason for the pneumothorax after AEC use is lung laceration due to more distal placement of AEC [5]. Fourth reason is air trapping in the distal airway segments leading to alveolar rupture and pneu- 
mothorax [4]. In our patient there was no tracheobronchial injury but there was oxygen supplementation through AEC, positive pressure ventilation with Ambu ${ }^{\circledR}$ bag and CPR. Pneumothorax in our patient may be the result of migration of the AEC with air trapping during emergent positive pressure ventilation, CPR leading to alveolar rupture and type 1 lung laceration. Pulmonary lacerations are potentially serious than the lung contusions as it causes disruption of the lung architecture leading to pneumothorax as air leaks out of laceration into the pleural space. Lung lacerations are divided into 4 types. Type 1 lung laceration are the most common lung laceration and it is also called compression rupture laceration; they are centrally located, elongated cavity of 2 $8 \mathrm{~cm}$ and filled with air or air with blood [6]. Videolaryngoscopy is becoming more and more useful tool in endotracheal tube exchange as well as intubation of difficult airway and it also prevents invasive complication of AEC [7]; in our patient we used video-laryngoscope and ACE as he was having supra-glottic collapse due to sleep apnea, supra glottic edema hence to facilitate reintubation.

The following measures are suggested to prevent or minimize the occurrence of barotraumas and alveolar rupture with the use of AEC. Endotraheal tube should be changed under the umbrella of pharyngeal oxygen insufflation, and if still oxygen has to be supplemented, it can be started with lower flow of 1 to 2 liters/minute. The AEC must be selected in proportion to the size of endotraheal tube and if there is any resistance in catheter negotiation, force should not be applied but the AEC should be withdrawn slightly $[8,9]$.

To conclude our case report rarely AEC use can cause life threatening injuries. Pneumothorax following the use of AEC is not always due to tracheobronchial trauma it can also occur due to alveolar injury.

\section{REFERENCES}

[1] Mort, T.C., Meistering, E.M. and Waberski, W.M. (1997)
Exchanging a tracheal tube in ICU patients; a comparison of two exchangers with direct laryngoscopy. Anesthesiology, 87, 2402.

[2] Benumof, J.L. (1999) Airway exchange catheters simple concept, potentially great danger. Anesthesiology, 91, 342344. doi:10.1097/00000542-199908000-00005

[3] Liudermilk, E.P., Hartmannsgruber, M., Stoltzfus, D.P. and Langevin, P.B. (1997) A prospective study of safety of tracheal extubation using a pediatric airway exchange catheter for patients with known difficult airway. Chest, 111, 1660-1665. doi:10.1378/chest.111.6.1660

[4] Harris, K., Chalhoub, M., Maroun, R. and Elsayegh, D. (2012). Endotracheal tube exchangers: Should we look for safer alternatives? Heart Lung, 41, 67-69. doi:10.1016/j.hrtlng.2011.06.005

[5] Nates, J.L. and Berner, D.K. (2001) Mishaps with ETT exchangers in ICU. Two case reports and review of literature. The Internet Journal of Anesthesiology, 5, 1.

[6] Thoongsuwan, N., Kanne, J.P. and Stem, E.J. (2005) Spectrum of blunt chest injuries. Journal of Thoracic Imaging, 20, 89-97. doi:10.1097/01.rti.0000148210.89718.f5

[7] Peral, D., Porcar, E., Bellver, J., Higueras, J., Onrubia, X. and Barbara, M. (2006) Glide scope video-laryngoscopy is useful in exchanging endotracheal tubes. Anesth Ana$\log$, 103, 1043-1044. doi:10.1213/01.ane.0000239066.91950.6a

[8] Baraka, A.S. (1999) Tension pneumothorax complicating jet ventilation via a Cook airway exchange catheter. Anesthesiology, 91, 557-558. doi:10.1097/00000542-199908000-00031

[9] Chin, J.H., Lee, E.H., Choi, D.K. and Choi, I.C. (2010) High frequency jet ventilation of one lung using a bronchial blocker of univent during carinal resection. Journal of Korean Medical Science, 25, 1083-1085. doi:10.3346/jkms.2010.25.7.1083 